\title{
THE USE OF THE GALLEY IN ELIZABETHAN PRINTING
}

$T T$ is well known that the usual practice of the modern printer when putting a book into type is to set up the whole of the copy in long or 'slip ' galleys, each containing from two to four pages of type, and to take proofs from these before dividing the matter into pages. This method has two important advantages. In the first place corrections can be made much more easily while the type is standing in galley than after it is in pages, and if the corrections involve the addition of new matter or the cancelling of portions already set up, this gives no special trouble, whereas were the matter already divided into pages a great part of that work might have to be done again. Secondly, if the type is to be set up in long galleys it is possible to divide the copy among a number of compositors who can work simultaneously, for it is, of course, unnecessary that the amount given to each should fill an exact number of pages. Were the work cut up into pages as composed it would, on the other hand, be necessary that each man's portion should end exactly at the foot of a page, a thing which could hardly be ensured by the most laborious counting of the words of the copy.

Now one of the many things that we do not know about Elizabethan printers is whether they ever used galleys in this way or not. The question is perhaps not of the first importance, but it has a certain interest from its bearing on the further question of the circumstances in which a book might be set up by two or more compositors working simultaneously and of the extent to which we are entitled to 


\section{The Use of the Galley in Elizabethan Printing}

suppose such a distribution of the work in explaining the peculiarities of spelling and arrangement which are sometimes met with in scattered portions of a text.

The point is not, of course, whether the Elizabethans used galleys at all, for they must have used something of the kind, but bow they used them. The ordinary composing stickand pictures of early printing-houses show that they used composing sticks-cannot have held more than some ten lines of pica at most, for the weight of the type would have made a greater depth of stick inconvenient to handle. ${ }^{1}$ When the stick was full the matter must have been transferred to some receptacle or other, whether it was called a galley or not is of no importance. What matters is whether it was merely transferred thither to wait until sufficient material was composed to form a page, or whether it was customary to make setting in galley a definite stage in the work, so that the matter of several pages might be standing in galley at the same time before any of it was divided up.

There is, unfortunately, not much external evidence as to " the technique of Elizabethan printing. In fact, so far as I know, there is no serious attempt whatever to describe the art earlier than that contained in the second volume of Moxon's Mechanick Exercises, 1683, but this, of course, is both

1 The usual height to paper of modern. English type is 0.92 in. I am indebted to Dr. Greg for the measurement of the only flat impression of an Elizabethan type that is known to me. This occurs in a copy of W. Lambarde's 'Apxacovorea, printed by John Day in 1568 . The impression measures 0.97 in. The int may have spread 2 trille, but on the other hand as the papper was printed damp the impression would be slightly smaller than' the type, so we can assume that 0.97 in. was about the actual height of the type and that therefore the weight of. Elizabethan type differed only to a negligible extent from that of modern type of an equal body. Now the average weight of a square inch of modern type is taken as $5 \mathrm{oz}$. Ten lines of Elizabethan pica of the ordinary measure of a quarto book would therefóre 'weigh"some 25 or $30 \mathrm{oz}$., which with the weight of the stick ituelf would be as much 28 would be convenient to hold. 


\section{The Use of the Galley in Elizabethan Printing . 99}

full and excellent. : While it cannot be said, in view of the date, to settle the question of Elizabethan practice, it is not without significance that Moxon evidently had no idea at all of the use of the galley to contain more than a single page of type at a time. His galleys are of the shape of a page and meant to contain one page each. He definitely lays down that when a compositor has accumulated in the galley the amount of type necessary for a page he should add a line of quadrats and the first word of the next page (with, when required, the signature). There is nowhere any suggestion of setting up a quantity of matter in; slip form and afterwards cutting it up into pages.

Another passage of Moxon is perhaps worth noting in this connexion. He advises that when a work is to be set in an unusual measure, instead of each compositor using his own stick, as was usual, one stick set to the required measure should be kept for the use of all the compositors employed on the job, who therefore must have worked in succession, not simultaneously. The assumption that the compositors would never be working simultaneously would hardly be made by a man familiar with the use of long galleys.

Now it seems quite improbable that if setting in long galleys had ever come into general use it should have so completely gone out by 1683 that Moxon's treatise should ignore it altogether. But, after all, this is but negative argument; and I think that, we can get positive proof that, at least, many books were paged as set up. Unfortunately, however, as so often happens in bibliography, our evidence of what happened is all derived from errors. A perfectly printed book would show no trace of the method by which it came into being. The, better-printed books, those, as a rule, which issued from the larger printing houses, contain little or no evidence as to whether they were set up page for page; or not, and it is precisely in such offices, with their larger 


\section{The Use of the Galley in Elizabethan Printing}

quantity of type, that, if anywhere, we might expect to find the slip galley in use. Let us, however, consider what traces page by page composition is likely to leave when carried out by a not too careful printer.

After finishing a page the compositor would have to add the catchword and, when necessary, the signature, to tie the page up, and to place it in safety on the imposing stone or elsewhere. This would take an appreciable time, and if the compositor was a careless person who did not trouble to mark accurately the point of the manuscript at which he had left off there seems a possibility that when he came to start the next page he would have forgotten exactly where to begin. At any rate we should expect serious errors of omission or repetition-as of whole lines of verse-to occur more frequently at a point where the work had been interrupted than elsewhere. Several such errors have been noticed ${ }^{1}$ at the ends of pages, and so far as my experience goes they certainly seem to occur more frequently there than in other situations. It is, however, of course impossible, without examining a very large number of books for the special purpose, to obtain satisfactory proof of this, so the argument is not by itself conclusive.

A further point is that when a page ends with a passage in type different from that of the bulk of the book it is common for both the signature and the catchword to be in this type, though the rule is not invariable. Now this would save trouble to the compositor if he added the signature and catchword at the time of finishing the page, but it would add considerably to his trouble-without so far as we can see any gain in the result-if he made up into page from galleys and for each catchword and signature had to consider and obtain the appropriate type. Though therefore this variation of the type of the signature line according to that

1 See Transactions, xii, p. 226. 


\section{The Use of the Galley in Elizabethan Printing IOI}

of the text is not conclusive evidence of setting straight in

- page, it is certainly more easily explained on such an assumption than otherwise.

We can, however, find much more satisfactory proof of setting direct into pages when we consider the form of the catchwords themselves. If a book is set up in long galleys, and then divided into pages, the catchword of any page must necessarily be taken from the first word immediately following the division, i.e. the first word of the next page; there is no other possible source for it. Now suppose the first word of this page happened to be incorrect, and yet a real word (i. e. having in itself nothing suspicious and yet wrong in its context), a compositor dividing, as we have supposed, long galleys into pages would have no idea that anything was amiss and would merely set up as catchword what he saw. We should therefore never find a catchword correct, while the first word of the following page was wrong, unless. indeed the error was one which the compositor of the catchword would necessarily recognize and avoid. On the other hand, if the catchword was inserted immediately the page was finished it would be taken from the -manuscript or original copy, and therefore would have every reason for being correct irrespective of whether the opening word of the next page was afterwards set up rightly or wrongly.

The most significant of all errors in this connexion are those in which a few words are omitted or repeated at the beginning of a page, an error which, as has already been said, is especially likely to happen when resuming composition after an interval; owing to carelessness in marking the place in the copy where the compositor had left off.

Instances of correct catchwords followed by erroneous page-openings are very numerous, and it requires little research to discover them. Those which follow may suffice as examples. They are chosen from a couple of books which 


\section{I02 The Use of the Galley in Elizabethan Printing}

I happen to have at hand, average examples of Elizabethan printing, neither specially good nor specially bad.

(1) The Enimie of Idleness by William Fulwood, Henry Bynneman, 1568.

B2 ends, 'to suche maner of people it were' [catcbevord but]. B2' begins 'were but simplicitie to gyue instructions'. Had the page been divided up from long galleys, the catchword would necessarily have been the incorrectly repeated 'were'.

$D_{4}$ ends a section describing how to write a certain kind of letter. The next page gives an example of the letter in question. Such examples throughout the book are normally headed The Example, but this particular one is headed merely Example. Nevertheless the catchword of $\mathrm{D}_{4}$ is Tbe.

$\mathrm{O}^{5}$ ends with 'accepta-', the catchword being 'ble'. The next page begins 'vnto me', the rest of 'acceptable' having accidentally been omitted. On the theory of paging from slip the catchword must have been 'vnto'.

Q8 ends ' that' [catcheoord ' your'], the next page beginning, by accidental repetition, 'that your'. The catchword 'your' could only have come direct from the manuscript.

(2) The Golden Grove by William Vaughan, S. Stafford, i608 (second edition, enlarged).

In this work the numerous quotations are normally printed in italics. Now sig. $P_{7}$ ends with two quotations, of which the first and so much as appears of the second on this page are inadvertently printed in roman, the catchword also being roman, but on turning the page we find that the quotation is correctly continued on the verso in italics. Evidently this catchword must have been added on completion of the page, for otherwise it would necessarily be taken from the first wyord of the next page and be in italics.

There is another test which we can sometimes apply in the case of plays, namely the form- of the speakers' names 
The Use of the Galley in Elizabethan Printing Io3

which appears in catchwords. Inspection of almost any early play shows that very little attempt was made at uniformity in the abbreviations used to represent the speakers' names. On the other hand, when in any particular passage a certain speaker's name recurs frequently, the compositor had, as we should naturally expect, some tendency to keep to the same form. He would presumably have this form in his mind, and while going straight ahead with his composition would not trouble much about the form (often perhaps only an initial) in which the name appeared in the manuscript before him. If, however, any interruption occurred in the work he might, so to say, make a fresh start with a different form. It follows, therefore, that in a work set up page by page, with the catchword added as each page was completed, we should expect that whenever a catchword included a speaker's name this name would be given the same form as had been generally used towards the foot of the page, without regard to the form of it with which the next page opens, If, on the other hand, the work had first been set up in long galley and cut up into pages afterwards, the catchword, being taken from the first line of the following page, should follow this exactly, without regard to the spelling. used on the previous page, for the compositor:would have no alternative form in his mind, and indeed might not know. the name for which the abbreviation stood. He would certainly have no inducement to alter it: :

It may be worth while to summarize the results of an examination of the catchwords of the First Folio of Shakespeare made from this point of view.

On 263 pages of the Folio the catchword (or the first part of it) is a speaker's name.

Apart from three non-significant errors, ${ }^{1}$ there are 82 cases where the form of the speaker's name occurring in the catch-

1 A wrong speaker on A6 and transposed letters on $S 6$ and mms. 


\section{I04 The Use of the Galley in Elizabethan Printing}

word differs either from that previously used on the page (or from the last form used on the page if there is more than one) or from that used at the head of the next page, or from both, but of these we may omit 12 from our consideration on the ground that the speaker's name does not occur previously on the page or that it occurs so far off that the compositor is unlikely to have the form used in his mind at the moment of setting up the catchword. We may also omit a further five as being in some way peculiar. ${ }^{1}$

If we now classify the remainder we find that we have 24 cases in which the catchword differs from both the preceding and following form of the speaker's name, 26 where it agrees with the preceding and differs from the following, and 15 where it differs from the preceding and agrees with the following form.

At first sight this seems rather inconclusive. It looks as if the catchword was sometimes set up in immediate connexion with the last line of its page and sometimes (though less often) taken from the first line of the next page; but when we consider more closely the chances of agreement or disagreement we see that our result is quite consistent with the theory that it was always set immediately after the last line, while it is evident that it sometimes must have been. We should not in any case expect perfect regularity. One method of setting should give merely a tendency to agreement with what has gone before, while the other should lead to a practical certainty of agreement with what follows. The

${ }^{1}$ i. c. on $\mathrm{E}_{2}{ }^{\mathrm{y}}, \mathrm{K}_{2}$, and $\mathrm{L}_{2}$, the catchword departs from the form used immediately above, but the printer in these particular cases had purposely shortened the word to save space: $\mathrm{O}_{5}$, Shylock has been called Sby., but in the catchword and in the following page he appears 2s I wo. This change must be due to the manuscript: n4, catchword is Queeme. She has previously appeared as $Q u$. and the next page begins $Q u e e n$. It is difficult to know how to class this, as the printer seems to use anything from $Q$. to Queene, according to whether he had a long or short line. 


\section{The Use of the Galley in Elizabethan Printing 105}

evidential value of agreement or disagreement in the two directions is therefore very different. We have a considerable number of catchwords which would be almost impossible on the assumption of galley setting, against a much smaller number which are not quite what we should expect, but are still possible, if the pages were dealt with separately. The balance of evidence is thus clearly in favour of the page by page method.

When, however, we look at certain particular cases the evidence seems to be conclusive.

On $\mathrm{K}^{\mathrm{r}}$ the last three speeches of Hero have erroneously the speaker's name Bero, while the next page has correctly Hero. The catchword has Bero. This cannot therefore have been set up from the first line of the next page.

On d6 the name of Prince Henry's companion is given in the only two cases in which it appears as Pointz, and so also in the catchword. The first speech of the next page has, however, the form Poines.

On vv2v we have a still more convincing case, for the catchword is Rodori. I, and in the Devonshire copy (Clarendon Press facsimile) these words do not appear at all on the following page, which begins 'And hell gnaw his bones, Performances are no kin together'. 'This was corrected in other copies, but it is evident that when the pages were being prepared for press there can have been nothing from which a compositor would take the catchword Rodori. I.

These three examples are in themselves sufficient proof that in the particular pages in which they occur the catchword was added immediately on completion of the page, and we may, I think, assume, until evidence is brought forward to the contrary, that the practice was followed throughout the whole book.

We have thus seen that three books taken from the years 1568,1608 , and 1623 show evidence that the matter was put 


\section{The Use of the Galley in Elizabethan Printing}

straight into page as composed, and was not first set up in long galleys and cut up into pages afterwards; and further that this was apparently the only system known to Moxon in 1683. While we cannot, of course, say that such evidence is sufficient to prove the universality of the method, we must I think assume, until evidence to the contrary is put forward, that it was the ordinary method in Elizabethan printing, and that the use of the long galley was unknown.

Assuming, then, that Elizabethan books were as a rule set up page by page and that long galleys were not used, it remains for us briefly to consider how this affects the question of the number of compositors who might be employed on a single job. It is evident that whether it affects it or not depends on the nature of the copy. When a printer had to reprint a work already in type and was following his original page for page, it was open to him to give every sheet, or even every page, to a different compositor, and all these might work simultaneously (assuming a sufficient number of type cases), for evidently each man's page would join on properly to those before and after it. Even in the case of a reprint which was not to follow the. original page for page, simultaneous composition by two compositors might sometimes be possible. A printer might, for example, wish to reduce-a book of ten sheets to one of eight, and might give the first five sheets to one compositor and the second five to another, instructing each to compress his five sheets into four. It is only when setting from a manuscript that such division between two or more men would, without the use of long galleys, involve such intricate calculation as to be impracticable. But even in such a case, though simultaneous composition by a number of compositors is impossible, there is clearly no reason why different men should not have worked at the job in succession.

Many reasons might cause work begun by one compositor 
The Use of the Galley in Elizabethan Printing ro7

to be continued by another. The most likely is perhaps that he first man had emptied his type-cases and needed to replenish them. It was probably usual, as it still is, that a compositor should himself distribute type into the cases which he used. If he did not do this, he ran the risk of the case being filled with letters wrongly distributed, which would cause much loss of time when he next used it. Now we have not sufficient evidence to enable us to calculate accurately the amount of matter which one pair of Elizabethan type cases would suffice to set up. Much depends on whether, as seems probable, a pair of cases ordinarily contained both roman and italic founts, and on whether when setting verse the compositor had at hand an additional supply of quads and spaces or was limited to those which his case would normally contain. In general, however, since the reach of an Elizabethan's arm and the length of his fingers were pretty much the same as those of a compositor of to-day, and since by 1580 the art was old enough for a reasonably convenient arrangement to have been evolved, there seems to be great probability that the dimensions of the Elizabethan type-case were not much different from those now customary. ${ }^{1}$ On this assumption we shall, I think, be fairly safe in supposing that at least three and not more than five ordinary quarto pages could be set up from one pair of cases. Probably we should not be far wrong in taking four as a fair average number.

Of course a compositor might not be limited to one pair of cases. On the other hand, the supply of type in all save the largest printing-houses was probably quite small, and each compositor would necessarily have the use of several

1 The dimensions given in Moxon's Mecbanick Exercises, 1683 , are $\frac{1}{2}$ in. longer, 2 in. wider, and $\frac{1}{8}$ in. deeper than those of the usual present-day rase, but they would probably have been somewhat more heavily built and would have held hardly any more type. 


\section{I08 The Use of the Galley in Elizabethan Printing}

(three at least) different sizes of book-type-probably in black letter and roman-apart from the founts of exceptional sizes which would be used by all the compositors as required. It seems, therefore, quite likely that one compositor might have the use of only two or three pairs of cases, at 'most, of a particular fount. He would therefore have to stop composition every dozen pages or oftener in order to replenish his cases by distributing work already printed off ; and if there was another compositor available, and the work was at all urgent, it would be natural for him to take it over. There would accordingly be nothing surprising if in a piece of Elizabethan printing we found indication of two different compositors setting alternate groups of some four to twelve pages. They would, however, have worked alternately, not simultaneously.

As we do not know whether the compositor was always or usually a distinct person from the pressman or whether each man took his turn at every kind of employment in the office, we can make no guess at the internal economy of the Elizabethan printing-house or whether such a change of compositor would be the usual thing or not. It may, however, be noted that distribution takes about a third of the time employed in composition, and that a compositor would almost certainly have had several other things to do besides the actual composition, namely, to make up the formes, see to the taking of proofs, if he did not himself pull them, and make the necessary corrections. The total amount of time accupied in these subsidiary tasks might amount to practically the same as that taken in the actual straightforward composition, and the employment of two men at the case alternately might therefore not involve any loss of time.

R. B. MCKerRow. 